\title{
Automated water Distribution System in Metro's using IOT
}

\author{
K.Suresh Kumar, K.Subhash, S.Tamilselvan, J.Sudhakar, P.Vignesh
}

\begin{abstract}
In urban regions, the water supply to home and business foundations are given at a settled stream rate. There are occurrences of overabundance water drawn by specific clients/clients for example water will be discharged informally, which is considered as water burglary. In this undertaking, it is proposed to build up an inserted based remote water observing and robbery counteractive action framework by taking the information of water supply at the purchaser/client end. The general goal of a conveyance framework is to convey healthy water to the buyer at specific territory and the inadequate amount and accomplish progression and most extreme inclusion at moderate expense. To accomplish the target the association needs to advance working strategies to guarantee that the framework can be worked palatably, work proficiently and ceaselessly beyond what many would consider possible at most reduced expense. Here we are utilizing PIC16F877A as our controller and furthermore, a couple of sensors are masterminded to distinguish the nearness of water in that specific pipeline. IR sensors are utilized to distinguish the water stream. Water ought to be discharged according to the directions by authority's for example for instance exchange long stretches of supply are given and just amid explicit timeframe however not day by day.

Keywords:
\end{abstract}

\section{INTRODUCTION}

Every one of the subtleties will have appeared in the web server utilizing the IOT module associated with the controller. With the goal that the experts can make an important move if there should be an occurrence of abuse. This is a propelled, inconvenience free, fit and overlooks framework for the water board. By utilizing all these failures can be kept away from.

This undertaking utilizes controlled $5 \mathrm{~V}, 500 \mathrm{~mA}$ power supply. Scaffold type full wave rectifier is utilized to redress the air conditioner output of optional of $230 / 12 \mathrm{~V}$ advance down transformer.

In this undertaking, we are planning a mechanized wateridentifying framework that permits distinguishing the water when the water lands at their region imply it will consequently send the alarm message to their cell phone. We additionally utilized valves for controlling the limit of water use in every zone. The same belief system and executed more highlights to it. For example, utilizing the IR sensor to recognize the stream of water. In the event that the

Revised Manuscript Received on April 12, 2019.

K.Suresh Kumar,Department of Computer Science and Engineering, V.S.B Engineering College, Karur, Tamil Nadu, India (Email: suresh8788@gmail.com)

K.Subhash,Department of Computer Science and Engineering, V.S.B Engineering College, Karur, Tamil Nadu, India

S.Tamilselvan,Department of Computer Science and Engineering, V.S.B Engineering College, Karur, Tamil Nadu, India

J.Sudhakar,Department of Computer Science and Engineering, V.S.B Engineering College, Karur, Tamil Nadu, India

P.Vignesh,Department of Computer Science and Engineering, V.S.B Engineering College, Karur, Tamil Nadu, India water did not go through the predetermined pipe in the zone or

Any damage means it will send an alert message to a TWAD board assistant along with pipe number. If the entire area will not receive water means, it will send a message to the higher authority. In the paper, we also include automated water usage monitoring systems, which will help to detect the amount of water used per area, and it will send the message to the higher authority.

In our project, we use the software as Embedded C, MPLAB and Preload. Using that, we will design the user login page and admin login page. In user login page it will display the amount of water used and whether the water will come to their area or not. For the admin login page, it will display the ph level of water, water release date and time along with area name and level of water in the water tank. The admin can also release the water in mobile itself.

\section{RELATED WORKS}

Mechanized Household Water Supply Monitoring and Billing System was proposed by TanvirRahman [At all] (2018). This paper depicts ask about in nuclear family water supply checking and charging. The segment of this endeavor is the modified trading of the DC water motor subject to the component of water present in the storehouse close by the introduction of the proportion of water used in each square. For the grandstand, a LCD Alphanumeric introduction was used. They also fused a set point of confinement of utilization for each floor and charging as shown by use.

Smart Water for Leakage Detection framework was proposed by Elias Farah [at all] (2018). They give meters on client administration associations with register the water utilization for charging purposes and to screen the dispersion Networks. Manual Meter Reading (MMR) or Automated Meter Reading (AMR) normally peruses meters. The manual water meter perusing is a dreary, costly and exceptionally work escalated occupation. The advancement of correspondence innovations empowers family units and water utilities to get to water utilization information through keen water meters or AMR frameworks. These shrewd meters can gather and impart continuously the recorded information. Meter perusers can gather from 600 to 1000 peruses every day by an administrator with a radio-prepared handheld PC. This number of meter peruses can reach around 20000 meters for every day utilizing a vehicle outfitted with specialized gadgets. In any case, these two AMR shapes remain a work cost procedure. The settled system gives the meter perusing at any recurrence interim

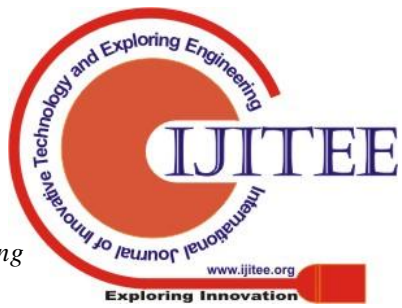


(hourly or significantly shorter periods like 10 seconds) and whenever of the day. Concerning the interchanges systems, water utilities utilize the Radio Frequency (RF) and the economically accessible remote and portable systems like GSM-GPRS, WI-FI, Zigbee-3G and 4G Long Term Evolution (LTE).

Savvy IOT water sprinkle and observing framework for bean stew plant was proposed by Handri Santos [at all] (2018). This framework is intended to supplant traditional bean stew sprinkle to programmed. The framework utilizing the dampness sensor to catch current dampness of the dirt, and information will be handled in Adriano as a microcontroller. This information will decide mugginess to open or close valve. This framework additionally utilizes a $\mathrm{pH}$ sensor, which is utilized to recognize causticity or alkalinity for a bean stew plant and EC sensor to decide the supplement arrangement of the dirt. The framework is additionally outfitted with killing $\mathrm{pH}$ and EC naturally. $\mathrm{PH}$ sensor and EC sensors will be computerized information accumulation, diagramming, and information examination. The outcome will be the open valve to killing liquid $\mathrm{PH}$ and EC. Handled information will be sent to the Web App by means of Ethernet Shield, Farmers can screen bean stew plants progressively utilizing a Smartphone. This paper centers around improving the utilization of water as required of stew plants and Internet of Things (IoT) can be utilized to information investigation for oversaw and controlled in detail and unequivocally by Sensor.

Water quality observing and waste administration utilizing IOT was proposed by Renjith Mohan [at all] (2017). Strategies, for example, Bio-remediation (utilization of microorganisms to evacuate or kill toxins) and vermin fertilizing the soil, which triggers the development of plants that ingest the contaminants, can be acquainted with the location the issue of decreasing the dimension of contaminants in the dirt. In any case, these arrangements require legitimate distinguishing proof of the contaminants. A broad sensor framework, which can screen the contaminants in the dirt just as the water bodies, is basic. This venture expects to plan and build up an IOT based framework that can detect the natural parameters and successfully convey data on the dimension of pollution and the nature of the water. Sensors to identify the hydrocarbons, synthetic and metal substance in the dirt can be coordinated into a dirt test for checking soil pollution. What's more, sensors for identifying $\mathrm{pH}$, conductivity, broke up oxygen, turbidity, and so forth can be utilized for checking the water quality in the streams, lakes, and so forth. In the site of intrigue. The plan, improvement, and usage of an IOT based framework will enable the specialists to find a way to perform appropriate waste administration of the influenced territory. We envision.

Creative Shunt Measurement for Residential Water Micro-Leakage Detection was proposed by A S. Alarefi [at all] (2017). They make a creative little scale spill acknowledgment structure for a private application that uses a ultrasonic stream meter in another shunt course of action is proposed. Not in the slightest degree like common water spill acknowledgment systems, the proposed robotized structure is exceedingly sensitive (recognized breaks of 1 $\mathrm{mL} / \mathrm{min}$.) and does not hinder the key stream. The little scale spill acknowledgment structure is completely motorized as it uses a: USB-controlled voltmeter, USBenergized stream meter, and USB-controlled switches. A rich component is that the system is remotely controlled over the Globe; thusly, allowing far reaching scale data social occasion and structure control. This structure sidesteps water spills on any scale, wherever on the planet. This last segment is passed the range of the complex customary revelation systems. The de-noising property of Wavelet change is done on the remotely accumulated data from the ultrasonic stream meter to remove unfortunate commotion.

In our undertaking, we will distinguish the stream of water for the whole territory. The element of this venture is consequently sending the message to encompassing region individuals if the water will go to their region. On the off chance that any harm in the water pipe implies the message will consequently send to boss water examiner alongside the area. We likewise incorporate programmed detecting of the measure of water utilized in every region and stream of water to all the territory in the equivalent appropriation that can be shown utilizing LCD Alphanumeric presentation. In this undertaking, it likewise settled online water quality sensors in water circulation frameworks has been perceived as one of the key parts of tainting cautioning frameworks for verifying general wellbeing. This examination proposes to investigate how the consideration of portable sensors for inline checking of different water quality parameters (e.g., remaining chlorine, $\mathrm{pH}$ ) can upgrade water appropriation framework security.

\section{PROPOSED SYSTEM}

The paper depicts our exploration in water observing and recognizing framework. In this undertaking, we utilize the PIC16F877A microcontroller pack. It will send a programmed water notice message to more recognizable specialist just as encompassing individuals utilizing IOT. Water level sensors and IR sensors were utilized to identify the dimension and the measure of water utilized individually. The component of this venture is naturally sending the alarm message to encompassing territory individuals if the water will go to their zone. In the wake of accepting the alarm message, the general population sign in to their client login page and review will automatically send to chief water analyst along with pipe number. We also include automatic sensing of the amount of water used in each area that can be displayed using HD44780 16character, 2-line (16X2) LCD display. 


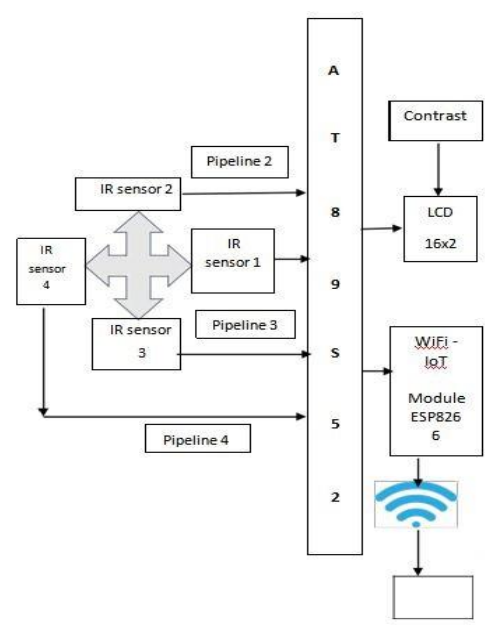

In this task it additionally fixed PH sensors in water circulation frameworks has been perceived as one of the key segments of defilement cautioning frameworks for verifying general wellbeing. On the off chance that the whole territory won't get water implies the alarm message sent to the more recognizable expert that can be seen in the administrator login page. In the administrator login page, it very well may be shown the ph dimension of water, water discharge date and time alongside region name, dimension of water in the water tank and measure of water utilized by every individuals. The administrator can likewise discharge the water in portable itself.

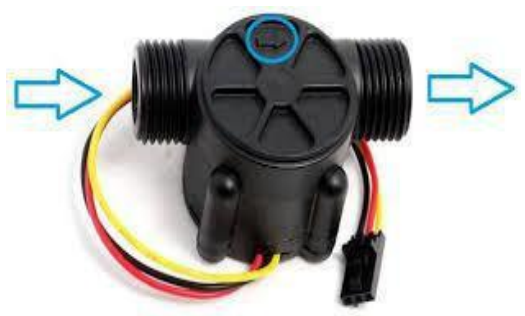

In this task it additionally fixed $\mathrm{PH}$ sensors in water circulation frameworks has been perceived as one of the key segments of defilement cautioning frameworks for verifying general wellbeing. On the off chance that the whole territory won't get water implies the alarm message sent to the more recognizable expert that can be seen in the administrator login page. In the administrator login page, it very well may be shown the ph dimension of water, water discharge date and time alongside region name, dimension of water in the water tank and measure of water utilized by every individuals. The administrator can likewise discharge the water in portable itself.

\section{WATER FLOW SENSOR:}

Water stream sensor includes a plastic valve body, a water rotor, and an entryway sway sensor. Exactly when water travels through the rotor, rotor rolls. Its speed changes with a substitute rate of the stream. The passage sway sensor yields the relating beat banner. Water stream sensors were set to each pipe.

\section{ARDUINO ATMEGA2560:}

Arduino is an open source PC gear and programming association, errand, and customer organize that plans and

makes single-board microcontrollers and microcontroller packs for structure propelled contraptions and natural articles that can distinguish and control inquiries in the physical world. Arduino board structures use an arrangement of microchips and controllers. The sheets are outfitted with sets of automated and straightforward data/yield (I/O) sticks that may be interfaced to various augmentation sheets (shields) and distinctive circuits. The microcontrollers are usually altered using a language of features from the programming tongues $\mathrm{C}$ and $\mathrm{C}++$. This is used to interface and complete the fundamental hardware of the observing framework.

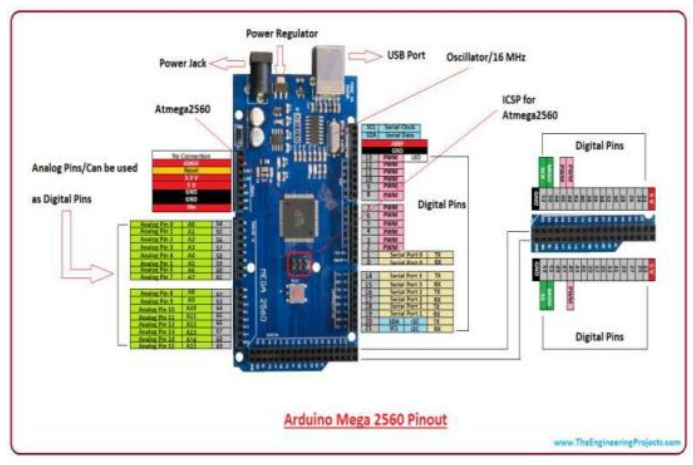

\section{WATER LEVEL SENSOR:}

Level sensors are used to recognize the component of substances that can stream. Such substances consolidate liquids, slurries, granular material and powders. Level estimations should be conceivable inside holders. 3 level sensors were settled on tanks which watched if water levels are at low/medium/anomalous states.

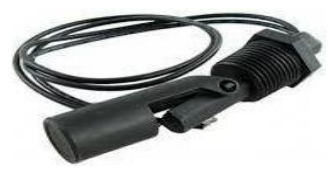

$R T C$ :

A RTC is an incorporated circuit, which works with a little coin cell/battery and considers continuous readings continually for a considerable length of time. It is utilized in our structure for perusing exact time and dates for when the water was filled, utilized and refilled by every region of the framework.

It additionally contains a little memory of 236 Bytes, which can store numbers, dates and time checks, which demonstrates to be ideal for time sensitive information passage assignments. On the product side, it accompanies free libraries to program it as the client wants.

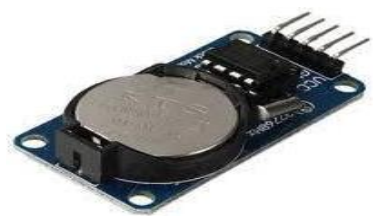




\section{WATER DETECTING SENSOR:}

A water locator is an electronic contraption that is planned to recognize the closeness of water and give an alert in order to allow the revultion of water spillage. A run of the mill structure is a little connection or contraption that untruths level on a story and relies upon the electrical conductivity of water to reduce the deterrent across more than two contacts. The device by then sounds fit for being heard alert together with giving forward motioning inside seeing enough water to interface the contacts. These are important in a routinely included district near any establishment that can discharge water, for instance, HVAC, water pipes, channel pipes, sweet machines, dehumidifiers, or water tanks.

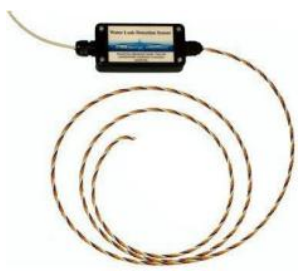

\section{PH SENSOR:}

$\mathrm{PH}$, by and large used for water estimations, is an extent of sharpness and alkalinity, or the searing and base present in a given game plan. It is normally spoken with a numeric scale stretching out from 0-14. The regard 7 addresses absence of predisposition. The numbers on the scale increase with growing alkalinity, while the numbers on the scale decay with extending acridity. Each unit of advancement addresses a ten times change in acridity or alkalinity. The $\mathrm{pH}$ regard is in like manner comparable to the negative logarithm of the hydrogen-molecule center or hydrogen-molecule development. PH regards for some fundamental courses of action are recorded in the table to the other side.

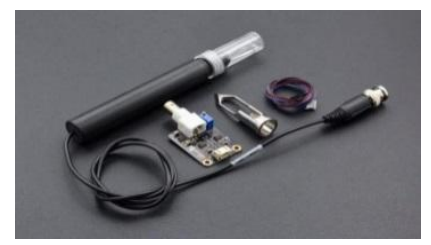

\section{RESULT ANALYSIS}

Here we are utilizing PIC16F877A as our controller and furthermore, a couple of sensors are masterminded to distinguish the nearness of water in that specific pipeline. IR sensors are utilized to distinguish the water stream. Water ought to be discharged according to the directions by authority's for example for instance exchange long stretches of supply are given and just amid explicit timeframe however not day by day.

\section{ADMIN LOGIN:}

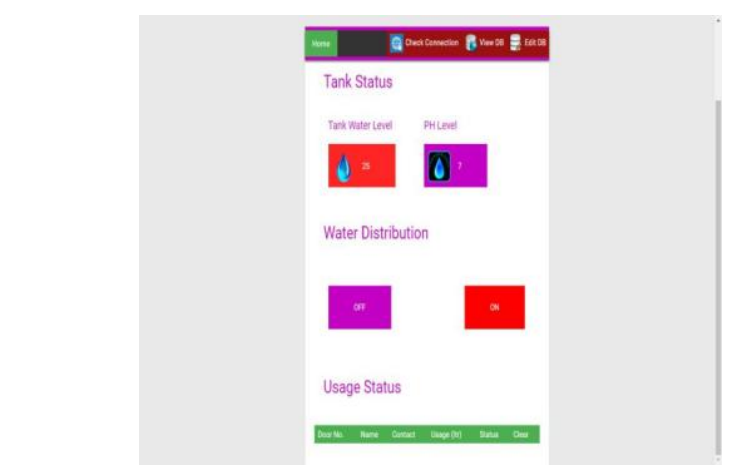

\section{USER LOGIN:}

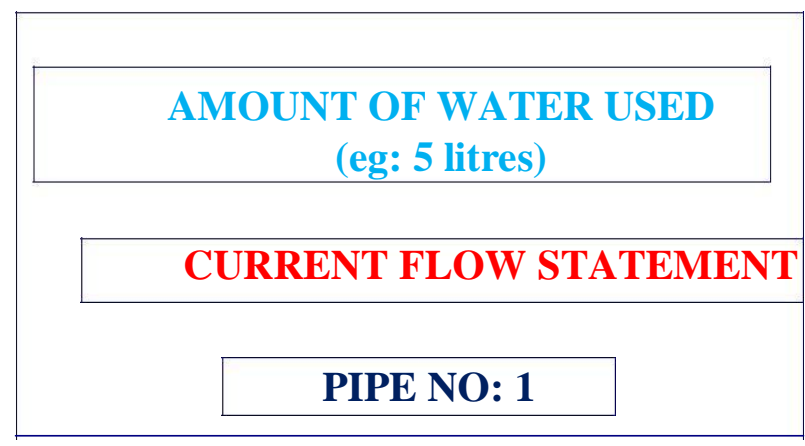

\section{REPAIR LOGIN:}

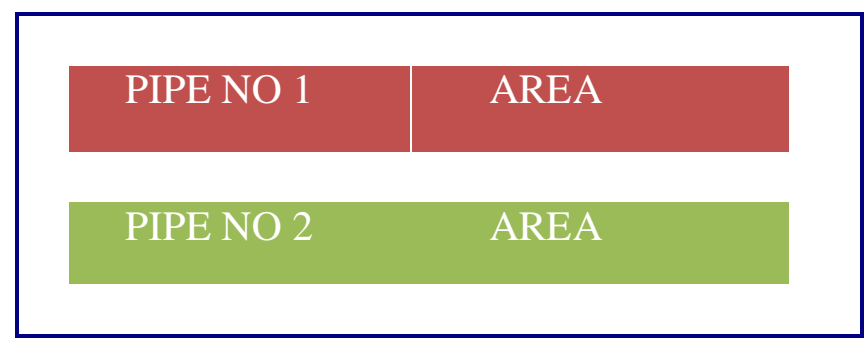

\section{CONCLUSION}

There are events of excess water drawn by explicit customers/customers for instance water will be released casually, which is considered as water robbery. In this endeavor, it is proposed to develop an embedded based remote water watching and burglary neutralizing move structure by making the data of water supply at the buyer/customer end. The general objective of a movement system is to pass on sound water to the purchaser at explicit domain and the insufficient sum and achieve movement and most outrageous incorporation at moderate cost. To achieve the objective the affiliation needs to propel working methodologies to ensure that the system can be worked agreeably, work capably and perpetually past what many would think about conceivable at most decreased cost. Here we are using PIC16F877A as our controller and besides, two or three sensors are engineered to recognize the proximity of water in that particular pipeline. IR sensors are used to recognize the water stream. Water should be released by the headings by power's for instance for example trade extended lengths of supply are given and just in the midst of express time span anyway not step by step. 


\section{REFERENCE:}

1. Water Quality Monitoring and Waste Management using IOT were proposed byMANEESHA V RAMESH, NIB K V AMRITA CENTER for Wireless Networks and Applications (AMRITAWNA) in the year of 2018.

2. Smart Water for Leakage Detection proposedby ELIASFARAH, ISAM SHAHROUR Laboratories de Genie Civil etgéo-Environnement (LGCGE) University de Lille 59650 Villeneuve d'Arcy, France in the year of 2018.

3. Smart IOT Water Sprinkle and Monitoring System for Chilli Plant was proposed by JUDIKAHERIANTO GULTOM Human-Computer Interaction Department Surya University in the year of 2017.

4. Innovative Shunt Measurement for Residential Water MicroLeakage Detection was proposed by SALMA A S. ALAREFI, member, IEEE School of Computer Science and Electronic Engineering University in the year of 2018.

5. SASEENDRAN, S., NITHYA, V. (2016). Automated water usage monitoring system. Publisher: IEE, 2016. Conference Location: Melmaruvathur, India.

6. STONECYPHER, L. (2015). Building an Electronic Water Level Controller. 2015.

7. SWAGATAM. (2015, 4 July). Build This Simple Electronic Water Level Controller. Retrieved from http://www.brighthubengineering .com /consum erappliances-electronics/68342-build-thissimple-electronicwater-level-controller.

8. RAHEJA, D.K. (2017, 15 September). Automated Water Pump Motor Controller.

9. Retrieved from http://electronicsforu.com/ electronics projects/auto matic-water-pump-motorcontroller.

10. G. O. CAMPOS, A. ZIMEK, J. SANDER, R. J. CAMPELLO, B. MICENKOVA,' E. SCHUBERT, I. Assent, and M. E. HOULE, "On the evaluation of unsupervised outlier detection: measures, datasets, and an empirical study," Data Mining and Knowledge Discovery, vol. 30, no. 4, pp. 891927, 2016. 